\title{
Implications of Substantially Increased Development Aid: The Case of Uganda
}

\section{Introduction}

The Commission for Africa envisages that development assistance must be doubled if Millennium Development Goals (MDGs) are to be met. To bridge the short to medium-term gap in financing (the difference between doubled aid and current donor commitments), it is proposed that the International Finance Facility (IFF) will use the value of long-term donor commitments to the IFF to raise large sums in the short to medium-term by issuing bonds on international capital markets. By bringing forward the value of long-term donor commitments, the IFF will enable a critical mass of aid to be invested in the short-term ("frontloading"), while leaving current donor commitments unaffected. The IFF will seek to use existing effective bilateral and multilateral mechanisms to disburse funds raised through the Facility and will ensure that disbursements reflect donor's preferred delivery channels.

For Uganda, the prospect of doubling aid through donor's preferred delivery channels conflicts with a number of our strategic objectives in our revised Poverty Eradication Action Plan (PEAP). The PEAP is Uganda's Poverty Reduction Strategy Paper (PRSP). The strategic objectives that conflict with increased aid are:

- Fiscal deficit reduction, private sector/exportled growth and reduced aid dependency.

- Improvements in efficiency/value-for-money of public expenditure and closer alignment to PEAP priorities.

- External debt sustainability.

\section{Fiscal deficit reduction, private sector/export-led growth and reduced aid dependency}

2.1 Fiscal deficit reduction, private sector/export-led growth

Since 1997/8, Uganda's fiscal deficit, excluding grants, has risen substantially by increasing expenditure (financed by donor aid) more rapidly than the growth in domestic revenues. The consequence of running a higher fiscal deficit, while at the same time maintaining inflation at or below 5 per cent, has been to increase Government's net issuance of securities (Treasury bills and long-term bonds) by over 500 per cent over the past five years and to increase the Bank of Uganda's (BOU) foreign exchange sales by 1,000 per cent. The issuing of securities and foreign exchange sales are the two instruments that the BOU uses to mop up excess liquidity from the domestic economy if it is to meet the inflation objective. As a result, interest rates have become sharply higher and more volatile, increasing the cost of private sector borrowing.

Although Uganda has enjoyed a sustained period of economic growth, this has been due largely to improved security, the restoration of macroeconomic stability, rehabilitation of existing production facilities and removal of economic distortions ("rebound growth"). These policy-induced improvements in resource allocation and resource deployment, reflected by high total factor productivity growth, have therefore been viewed as movements towards the production possibility frontier rather than as an outward shift in productive capacity. As Uganda enters its second more challenging phase of growth, sustaining the high growth rates of the last 15 years will require strong

IDS Bulletin Vol 36 No 3 September 2005 (C) Institute of Development Studies 
private investment to shift the production possibility frontier outwards, which in turn requires low and stable interest rates as a result of a reduction in the fiscal deficit.

Further, a recent study suggests that Uganda's exchange rate has been overvalued since the late 1990s and attributes a considerable proportion of this overvaluation to the behaviour of aid flows. Since August 2003, the general trend of a depreciating nominal Shilling (against the US dollar) has been abruptly reversed. By December 2004, the Shilling had appreciated by approx. 13 per cent against the US dollar, caused primarily by the size of the government's fiscal deficit, rendering the tea, tobacco, maize and fish export sectors temporarily unprofitable and leading to lower farmgate prices. The damage to the export sector caused by the appreciation and subsequent reduction in farmgate prices has clearly illustrated that Uganda's large aidfinanced fiscal deficit is not necessarily compatible with the objectives of poverty reduction and strong export-led growth, even though its purpose is to finance expenditures aimed at poverty reduction. While export competitiveness can be enhanced in the long term by improving infrastructure (roads, rail, air and electricity) financed by an increase in donor aid, exchange rate appreciation during this time lag could be sufficiently damaging to "kill" export sectors before any long-term gains are realised.

Thus it is clear in Uganda that a high fiscal deficit, based on current aid levels, directly undermines a number of the supporting economic conditions required for strong private investment, export-led growth and structural transformation. As a result, Uganda aims gradually to reduce its fiscal deficit over the medium and long term by prioritising expenditure, mobilising additional domestic resources and reducing dependence on donor aid. In other words, substantially increasing donor aid is not the solution to sustainable poverty reduction in Uganda.

In terms of what I have read to date on the Commission for Africa, the impact on macroeconomic management has been grossly underplayed, especially in terms of monetary policy to "mop up" excess liquidity and reduce exchange rate volatility created by higher aid inflows - and consequently, the impact on the private sector and export sector has been understated. For countries contemplating an increase in donor aid, rigorous analysis should be undertaken to project inflation, interest rates and the nominal and real exchange rates to understand fully how private investment, exports, competitiveness and poverty levels are likely to be affected. We should not pin too much hope on increasing the import content of public expenditure as a way to mitigate some of the negative effects of increased aid. In Uganda, a large share of poverty-reducing expenditure is on nonimportable/non-tradable goods and services. Programmes such as Universal Primary Education (UPE), Primary Health Care (PHC), the Road Sector Development Plan (RSDP) and the Plan for the Modernisation of Agriculture (PMA) are primarily wage intensive, as they require the recruitment of skilled personnel such as teachers, health workers and extension workers. Government cannot therefore switch its expenditures in these programmes away from wages to imports in any significant way, without compromising its ability to deliver key services through these programmes. In addition, the capital components of these programmes involve expenditures that do not have high import content. Classroom construction, health centre construction, road development and road maintenance require domestic non-tradable goods such as cement, bricks and timber. Further, shifting public expenditure towards imports restricts procurement and undermines the local economy by reducing the multiplier effect of government expenditure.

\subsection{Reduced aid dependency}

Achieving a lower fiscal deficit is not the only factor behind Uganda's objective to reduce donor dependency from its current level of almost 50 per cent. High dependency on donor aid has increased the vulnerability of the budget to a sudden cutback in donor aid. While a temporary reduction in aid could be absorbed through a limited rundown of the central bank's foreign exchange reserves, a cutback in aid which lasted for much more than one year would force government to make severe budget cuts. In addition, excessive aid dependency inevitably impinges on the sovereignty of the aid recipient and constrains its economic and budgetary choices, which is not consistent with the development of a healthy and equal relationship between aid recipients and the donors. Reducing dependence on aid therefore is crucial for the development of democracy and improving the accountability of government. 
While Uganda's position is clear on reducing and not increasing aid dependency, dependency will only be reduced gradually as there are limitations to the growth in domestic revenue. ${ }^{1}$ It would not be prudent to expect increased domestic revenue to "fill the gap" left by donor inflows after the initial "front-loading" of aid tapers off, as the most likely outcome would be domestic revenue lagging behind over-optimistic projections, necessitating a large fiscal cutback and reduction in key spending programmes. For countries which decide to decrease aid dependency, it will be crucial to align increased aid-financed expenditure with domestic revenue performance to ensure at least some minimum level of fiscal sustainability. For example, countries should seriously consider reducing aid-financed expenditure if domestic revenue performance over the medium term falls below expectations; otherwise budgets will become vulnerable to cutbacks in donor aid. Clearly incentives such as this are needed to encourage domestic revenue mobilisation and avoid governments "free-riding" on the generosity of donors. In fact, Uganda's standpoint is heavily influenced by its own disappointing revenue performance since 1997/8 (revenue/Gross Domestic Product (GDP) ratio has only increased by 2 per cent of GDP), the same period over which donor inflows increased substantially.

\section{Improvements in efficiency/ value-for-money of public expenditure and closer alignment to PEAP priorities}

Uganda's deficit reduction strategy inevitably limits public expenditure growth (including donor aid), and consequently strong emphasis is placed on the quality rather than the quantity of expenditure, especially for donor projects. Any further increase in aid to Uganda would seriously impede government's efforts to improve efficiency/valuefor-money and increase alignment to PEAP priorities. There are two main strands to this issue.

\subsection{Absorptive capacity}

First, increasing public expenditure (whether financed by domestic resources or donor aid) and maintaining or improving value-for-money requires an equal rise in absorptive capacity, within both the public service and the domestic economy. In Uganda, the expansion of government expenditure in the mid-1990s, mainly funded by an increase in donor aid, undoubtedly helped to fund key government priorities. However, growth in public spending outstripped the implementation capacity in the public sector and in the wider economy, with the result that costs were driven up and the quality of many development projects was unacceptably poor. Capacity constraints have been particularly acute in the roads sector, where construction costs have risen rapidly, cost overruns are commonplace and there are long delays before donor-funded road projects can get off the ground. Even some of the money being channelled into key povertyeradicating programmes has not been well spent, resulting for example in poorly constructed classrooms.

Thus even at current aid levels, Uganda cannot effectively absorb donor inflows; a doubling of aid would be disastrous for efforts to improve valuefor-money and would set unit costs at unsustainably high levels. Although the Commission for Africa has proposed recommendations for enhancing the quality of public institutions and capacity to increase the effectiveness of extra funds, in practice, increasing absorptive capacity is a long-term process. The Commission should seriously reexamine the IFF plan to "front-load" aid in the short term, as this allows very little time for the public sector and economy to develop absorptive capacity.

On a practical level, the Commission must come up with a robust framework for assessing the absorptive capacity of each country, and all stakeholders must agree on a set of indicators to monitor value-for-money on a regular basis. This is far from a simple task. Although Uganda has had some success with tracking studies and strengthening formal accountability, unit costs of inputs and outputs are rarely measured, never mind scrutinised, and even in a sector as large as roads with substantial donor support, the sector has failed to develop a road construction price index. Similar to the issue of whether aid-financed expenditure should be adjusted downwards if domestic revenue performance is below target, there should also be a clear agreement to scale back aid-financed expenditure if there are clear signs of absorption constraints.

\subsection{Delivery channel of aid}

Given that the IFF will ensure that disbursements reflect donors' preferred delivery channels - and 
project support is the preferred channel for several donors - a large increase in aid could herald a proliferation of costly, misaligned projects. In Uganda, donor projects frequently comprise low priority expenditures that are not explicit objectives of our PEAP and have much higher unit costs than general government budget expenditure, including budget support. The counterpart funding and recurrent cost implications of such projects have to be met through the government budget and often crowd out essential spending in priority areas. A prime example is the roads sector where an imbalance between capital projects and operational expenditures has led to severe underfunding of essential road maintenance.

To ensure better alignment of projects with development priorities, as well as to strengthen sector budgeting, Uganda has started to integrate project aid into medium-term sector expenditure ceilings. All sector expenditure ceilings are determined on the basis of allocating a centrally determined budget resource envelope for aggregate government expenditures, including donor projects, according to the government's strategic spending priorities, which reflect PEAP priorities. This means that sector expenditure ceilings are determined independently of the resources, which any donors propose to give to a sector, whether through project aid or sector budget support. In the event that the sector takes on donor-funded projects greater than the value of these projects in its sector expenditure ceiling, its government budget ceiling will be cut accordingly to maintain the integrity of the overall expenditure ceiling. ${ }^{2}$

All of this makes it inevitable that an increase in donor projects financed by the proposed increases in aid would cause Uganda to turn down projects that are either not aligned with key priorities or are too costly within the sector's predetermined ceiling. For example, to accommodate the Global Funds programme within Uganda's health sector ceiling, the programme has been rationalised to ensure additionality by identifying gaps in services rather than by duplicating existing services.

\section{External debt sustainability}

The IFF is also likely to herald not just increased support for projects, but also an increase in loans to developing countries, since loans are the preferred delivery channel of aid for major donors such as the World Bank and the African Development Bank. ${ }^{3}$
This poses a serious challenge to many developing countries as external debt management remains weak in terms of coordination between external debt contraction and development priorities and external debt sustainability strategies.

In response to our external debt burden reaching unsustainable levels despite enhanced heavily indebted poor countries (HIPC) relief, Uganda has placed a cap on all new borrowings and will limit loans to only those that contribute directly to productive enhancement. Therefore Uganda will in future reject not just project aid, but loans that either do not contribute to productive enhancement or exceed the borrowing cap.

Uganda is concerned by the Commission for Africa's proposal for debt relief, 100 per cent debt service cancellation to 2015, as this could lead to public expenditure reaching unsustainable levels by 2015 when the resumption of external debt service will be felt as a "fiscal shock" leading to expenditure cutbacks. The Commission should focus more on immediately cancelling a proportion of the outstanding debt of debtor countries, allowing countries to service external debt at lower levels and maintain fiscal stability.

\section{Summary and the way forward}

Although poverty levels are still high in Uganda and government remains firmly committed to reducing poverty and meeting MDG targets as quickly as possible, substantially increasing donor aid is not the way to achieve these goals in a sustainable manner.

To recap, current aid levels in Uganda are already directly undermining a number of the supporting economic conditions required for strong private investment and export-led growth. Increasing the import content of aid-financed expenditure is not a viable option. The expansion of aid-financed public expenditure has outstripped absorptive capacity in the public sector and the wider economy and, together with a proliferation of donor projects, unit costs have been driven up resulting in poor value-for-money and many of the projects have not been aligned to specific development priorities. (For this reason, the Commission for Africa must rethink "front-loading"). Further, despite HIPC and enhanced HIPC relief, Uganda's external debt burden has again become unsustainable. The revised PEAP sets out how Uganda intends to improve capacity within the public service - a long-term 
process involving pay reform and capacity-building at both central and local government levels. Uganda is trying to rationalise public sector structures and make use of existing administrative structures. Therefore the creation of additional public agencies is not the path Uganda will take to increasing capacity.

To confront our challenges, Uganda aims gradually to reduce its fiscal deficit over the medium and long terms by prioritising expenditure on those activities that contribute directly to poverty eradication (i.e. focusing on quality rather than quantity of expenditure), mobilising additional domestic resources, and reducing dependence on donor aid. Uganda believes that this is the optimal strategy to reduce poverty sustainably and to meet MDG targets. Thus it is up to Uganda to decide how much aid it should receive and not the donors.

Given that Uganda does not expect to escape aid-dependency quickly as there are limitations to the growth in domestic revenue, the major challenge in terms of development aid is to improve the quality

\section{Notes}

* The views expressed in this article are those of the author. They do not in any way reflect the views of the Ministry of Finance, Planning and Economic Development, Uganda or of the Government of Uganda.

1. The constraints to revenue generation in Uganda are structural (large informal sector), institutional (administrative capacity) and political.

2. The integration of project aid within Uganda's MediumTerm Expenditure Framework (MTEF) is expected to bring the following benefits: (1) Externally funded projects will be made subject to a hard budget constraint and normal budgetary controls will be imposed upon them. This process will enhance budget discipline, as line of current levels of aid-financed expenditure. In order to improve effectiveness of aid by increasing alignment to development priorities and increasing efficiency, Uganda's preferred modality of aid is budget support grants, as they directly fund government's expenditure priorities, as guided by the PEAP - and further, do not contribute to Uganda's external debt burden. Uganda's policy therefore is to encourage donors to shift to budget support, particularly budget support grants, and to be more selective about the projects it accepts through the integration of project aid into mediumterm sector expenditure ceilings. However, this does not mean that Uganda would rapidly expand aid-financed public expenditure if increased aid all came in the form of budget support grants, as this would not be consistent with our deficit reduction strategy. Rather, government savings with the Bank of Uganda would increase and this amount would be drawn down in future years to finance resource shortfalls.

ministries will not be able to circumvent budget ceilings by lobbying donors for project aid instead of budget support. (2) Given the hard budget constraint imposed by the sector ceiling, the integration of projects will encourage ministries and agencies within each sector to compete for expenditure demands when accepting a donor-funded project, which gives them an incentive to ensure that the accepted projects are in line with the sector's spending priorities. (3) The integration of projects will encourage donors and line ministries to shift within the sector from project aid to budget support in line with Government's desired policy.

3. Although the Commission supports an increase in grant finance to limit the build-up of additional external debt. 